\title{
Controle farmacognóstico das raízes de Heteropteris aphrodisiaca O. Mach. (Malpighiaceae)
}

\author{
Luís C. Marques ${ }^{1}$, Celina de Pieri ${ }^{1}$, Walter A. Roman-Júnior ${ }^{2}$, Mara L. C. Cardoso ${ }^{1}$, Maria \\ A. Milaneze-Gutierre ${ }^{3}$, João C. P. Mello ${ }^{1 *}$
}

\author{
${ }^{1}$ Laboratório de Farmacognosia, Departamento de Farmácia e Farmacologia, Universidade Estadual de \\ Maringá, Avenida Colombo 5790, 87020-900, Maringá, PR, Brasil, \\ ${ }^{2}$ Universidade Regional Integrada, Campus de Frederico Westphalen, Rua Assis Brasil 709, \\ 98400-000, Frederico Westphalen, RS, Brasil, \\ ${ }^{3}$ Departamento de Biologia, Universidade Estadual de Maringá, Avenida Colombo 5790, \\ 87020-900, Maringá, PR, Brasil
}

\begin{abstract}
RESUMO: As raízes de Heteropteris aphrodisiaca, denominadas de "nó-de-cachorro", pela semelhança morfológica com o pênis canino, são usadas popularmente com ação afrodisíaca, estimulante e no tratamento de disenterias, tendo este estudo o objetivo de caracterizá-las morfoanatômica e fisico-quimicamente. Para as análises foram elaboradas lâminas histológicas e analisados extratos aquosos, hidro-etanólicos e cetônicos obtidos a partir de amostras coletadas no estado do Mato Grosso, nas diferentes estações do ano. Tais raízes são tuberosas, cilíndricas e recobertas por súber estriado de coloração marrom-escura. O córtex, composto por tecido parenquimático, não apresenta elementos esclerificados, mas mostra-se com abundância de drusas e cristais prismáticos de oxalato de cálcio, bem como de idioblastos contendo polifenóis. No xilema secundário são abundantes as fibras gelatinosas, típicas de raízes de espécies do cerrado brasileiro. As análises físico-químicas revelaram maiores perdas por dessecação nas amostras coletadas no verão e na primavera. A água foi considerada o melhor líquido extrator, o teor de cinzas totais das amostras variou de $3,4 \%$ no verão a $5,3 \%$ no outono, enquanto que os teores de polifenóis totais foram maiores na primavera (10,2\%) que nas demais estações, sugerese esta estação como a mais apropriada para a coleta da droga vegetal. Análises cromatográficas em camada delgada e líquida de alta eficiência foram realizadas empregando-se marcadores flavonoídicos neoastilbina, astilbina e isoastilbina, com valores de $R_{\mathrm{f}}$ de $0,60,0,68$ e 0,74 , e tempos de retenção de: $16,44,16,91$ e 18,08 min, respectivamente.
\end{abstract}

Unitermos: Heteropteris aphrodisiaca, Malpighiaceae, "nó-de-cachorro", controle de qualidade farmacognóstico, CCD, CLAE, flavonóides.

\begin{abstract}
Pharmacognostic analysis of the roots of Heteropteris aphrodisiaca O. Mach. (Malpighiaceae)". The roots of Heteropteris aphrodisiaca, called "nó-de-cachorro"(dog-knot) for their morphological similarity to the canine penis, are used in popular medicine as an aphrodisiac or stimulant, and to treat dysentery. The objective of the present study was to characterize these roots morphoanatomically and physico-chemically. For the analyses, histological slides were prepared, and aqueous, hydro-ethanol, and ketone extracts were analyzed, from root samples collected in the state of Mato Grosso, in different seasons of the year. The roots are tuberous, cylindrical, and covered with a striated suber. The cortex, composed of parenchymatous tissue, has no sclerified elements, but shows abundant druses and prismatic crystals of calcium oxalate, as well as idioblasts containing polyphenols. In the secondary xylem, gelatinous fibers are abundant, typical for the roots of species of the Brazilian cerrado (savanna). The physical and chemical analyses revealed greater losses through desiccation in the samples collected in spring and summer. Water was the best extraction liquid. Total ash content of the samples ranged from $3.4 \%$ in summer to $5.3 \%$ in autumn. Total phenol content was higher in spring $(10.2 \%)$, suggesting this season as the most appropriate to harvest the plant drug. Chromatographic analyses through TLC and HPLC were employed using the flavonoids neoastilbin, astilbin, and isoastilbin as markers. The $R_{f}$ values were $0.60,0.68$ and 0.74 , and the retention time were $16.44,16.91$ and $18.08 \mathrm{~min}$, respectively.
\end{abstract}

Keywords: Heteropteris aphrodisiaca, Malpighiaceae, "nó-de-cachorro", pharmacognostic analysis, TLC, HPLC, flavonoids. 


\section{INTRODUÇ̃̃O}

A primeira descrição sobre a espécie vegetal conhecida popularmente por "nó-de-cachorro" foi realizada em 1920 por Hoehne, com a afirmação: "Este material goza da fama de ser altamente estimulante e afrodisíaco, razão pela qual o vendem em doses verdadeiramente homeopáticas e por preço elevado". $\mathrm{Na}$ época, em termos de identificação botânica, havia a sugestão que tal espécie pudesse ser Davilla rugosa Poir., da família Dilleniaceae. Hoehne (1920) relatava ainda: "Para os mesmos fins e com idêntico nome vulgar usam, em Mato Grosso, o caule e as raízes de uma Malpighiaceae".

A partir de 1929, o professor Othon Machado trabalhou na identificação botânica do "nó-decachorro", conseguindo obter amostras floridas somente em 1948, originárias do estado do Mato Grosso. Machado (1948-1949) observou que esta pertencia ao gênero Heteropteris Kunth (Malpighiaceae) e concluiu tratar-se de uma espécie nova, classificando-a como H. aphrodisiaca O. Mach. e a definindo como "planta medicinal, útil principalmente como afrodisíaco e contra o esgotamento nervoso". Segundo Corrêa (1984), as espécies do gênero Heteropteris podem ser encontradas nos estados de Mato Grosso, Goiás e São Paulo.

As raízes de $H$. aphrodisiaca são irregulares com partes engrossadas e constrições, de onde advém seu nome popular, por semelhança ao pênis canino. São utilizadas, na medicina popular, como afrodisíaco na forma de garrafadas (curtidas na cachaça) e no tratamento da debilidade nervosa, como depurativo e para o tratamento de disenterias e diabetes (Rizzini; Mors, 1976; Macedo; Ferreira, 2004).

Rizzini (1983) menciona as raízes de $H$. aphrodisiaca em estudos etnobotânicos, sendo uma das 65 espécies vegetais psicoativas observadas no Brasil, classificada como estimulante, cujo uso se assemelha ao das plantas adaptógenas ou resistógenas.

Em relação ao conhecimento científico desta espécie, citam-se os trabalhos de Galvão et al. (1996, 2002), que avaliaram os efeitos do extrato desta droga (extrato liofilizado BST-0298 - Patente requerida \#PI9803518-5) sobre a aprendizagem e memória de ratos jovens e idosos, obtendo-se uma melhora significativa dos animais tratados avaliados nos modelos de esquiva passiva e labirinto em "T" (discriminação direitaesquerda) (Galvão et al., 2002).

Outro efeito observado se refere ao aumento na atividade antioxidante em estresse oxidativo e defesas antioxidantes em cérebros de ratos jovens e idosos, medidos por meio do teste da lipoperoxidação in vitro (Mattei et al., 2001).

Recentemente, Roman-Júnior et al. (2005) isolaram um novo nitrocomposto [2,3,4,6-tetra- $O$ (3-nitropropanoíla)-O- $\beta$-D-glucopiranosídeo] das raízes de $H$. aphrodisiaca, com comprovada atividade antibacteriana. Esta mesma substância demonstrou ter moderada atividade antiviral contra poliovírus tipo $1 \mathrm{e}$ herpes vírus bovino tipo 1 (Melo et al., 2006).

Em termos de controle de qualidade farmacognóstico, Marques et al. (1996) verificaram, principalmente em atacadistas e ambulantes da cidade de São Paulo, a ocorrência da troca das raízes de $H$. aphrodisiaca por rizomas da espécie daninha Vernonia cognata Less., da família Asteraceae (Compositae). Estudos preliminares, com roedores, indicaram que a espécie adulterante tem potencial de toxicidade, pois apresenta $\mathrm{DL}_{50}$ baixa, fato que indica risco no consumo de lotes desta droga vegetal sem a devida e necessária identificação.

Neste contexto, este estudo objetivou a caracterização morfoanatômica e fisico-química das raízes de $H$. aphrodisiaca, fornecendo parâmetros que auxiliem a avaliação da sua qualidade.

\section{MATERIAL E MÉTODOS}

\section{Obtenção das amostras}

As amostras de $H$. aphrodisiaca foram coletadas nas quatro estações entre os anos de 1998 e 1999, em Santo Antônio do Leverger (MT) (30²8'31'”S e $\left.51^{\circ} 35^{\prime} 25^{\prime \prime} \mathrm{W}\right)$. Ramos em estádio reprodutivo foram preparados na forma de exsicatas, estando depositados sob o $\mathrm{n}^{\circ} 22.181$ (HUFMT) no Herbário Central da Universidade Federal de Mato Grosso, em Cuiabá (Figura 1A).

\section{Caracterização morfoanatômica e físico-química}

Para a caracterização das raízes de $H$. aphrodisiaca as amostras foram fixadas em FAA 50 e posteriormente conservadas em etanol 70\% (Johansen, 1940) ou parcialmente fragmentadas, secas em temperatura ambiente $\left(25 \pm 2{ }^{\circ} \mathrm{C}\right)$ por um período de sete dias, seguido de moagem em moinho de martelos (Tigre ASN-5, peneira $\mathrm{n}^{\circ} 1$ ).

Para as avaliações organoléptica, macroscópica e microscópica seguiram as recomendações usuais da farmacognosia (Oliveira et al., 1991), sendo utilizadas as amostras coletadas no outono. Para a análise ao microscópio óptico, foram obtidas secções anatômicas à mão livre, com auxílio de lâminas de barbear, das amostras conservadas em etanol $70 \%$. Essas foram descoradas com hipoclorito de sódio (30\% a partir de solução comercial) e coradas com azul de astra e safranina (safrablau) (Kraus; Arduin, 1997). A diafanização do pó da droga vegetal foi realizada segundo as indicações de Handro (1967) para tecidos foliares, mas utilizando-se o safrablau como corante.

Os testes microquímicos foram realizados com as amostras conservadas em etanol $70 \%$, sendo utilizado lugol para detecção de grãos de amido, cloreto 
férrico a $10 \%$ para polifenóis, Sudan IV glicerinado para substâncias lipídicas, cloreto de zinco iodado para celulose e lignina, e solução de ácido sulfúrico (5-10\%) para identificação da composição dos cristais de cálcio presentes nos tecidos (Johansen, 1940; Kraus; Arduin, 1997).

A análise fisico-química, com cinco repetições, incluiu: a) perda por dessecação; b) teor de polifenóis totais; c) teor de extrativos aquoso a quente; d) teor de extrativos com diferentes líquidos extratores sob refluxo; e) cinzas totais e cinzas insolúveis; f) índice de espuma; g) triagem química preliminar; h) análise granulométrica (Glasl, 1983; WHO, 1992; Farmacopéia Brasileira, 1998; Harborne, 1998).

Para as análises cromatográficas foi empregada a fração acetato de etila, obtida a partir do particionamento do extrato etanólico a $50 \%(10 \% ; \mathrm{p} / \mathrm{v})$. As análises cromatográficas foram realizadas, seguindose os seguintes parâmetros: CCD em cromatofolha de alumínio contendo gel de sílica $\mathrm{F}_{254}$; sistema eluente: acetato de etila: ácido fórmico: água (90:5:5; v/v); revelador: solução de cloreto de alumínio a $1 \%$ em etanol e reagente natural (Wagner et al., 1983). Para a cromatografia líquida de alta eficiência as seguintes condições foram utilizadas: Bombas Shimadzu ClasseVP, detetor UV/VIS SPD-10AVP; volume de injeção 20 $\mu \mathrm{L}$; coluna: Lichrospher RP-18 Phenomenex ${ }^{\circledR}, 5 \mu \mathrm{M}$, $250 \times 4,6 \mathrm{~mm}$; sistema gradiente multilinear: Bomba A: ácido acético 5\%; Bomba B: $\mathrm{MeOH} \mathrm{10 \%} \mathrm{(5} \mathrm{min),}$ $50 \%$ (15 min), 100\% (20-25 min), MeOH 50\% (30 min) e MeOH 10\% (40 min); detecção: $280 \mathrm{~nm}$; vazão: 1,2 $\mathrm{mL} / \mathrm{min}$ ). Como marcadores fitoquímicos utilizaramse os flavonóides isoastilbina, astilbina e neoastilbina (Roman-Júnior, 2003).

\section{RESULTADOS E DISCUSSÃO}

\section{Descrição organoléptica, macroscópica microscópica}

As amostras de raízes analisadas apresentam-se com dimensões entre 3,0 a $30 \mathrm{~cm}$ de comprimento por 0,5 a 2,0 cm de diâmetro, tomando-se por base as partes mais espessadas. As raízes tuberosas são de formato cilíndrico, irregulares, com partes mais espessadas e outras com estreitamentos acentuados (constrições) (Figura 1B), as quais distam, entre si, de 1,0 a pouco mais que 7,0 $\mathrm{cm}$. Quando frescas ou conservadas em etanol 70\%, as amostras de raízes mostram-se de coloração marrom acinzentada, apresentando odor próprio, intenso, não chegando a ser desagradável. A análise externa revelou que o súber encontra-se irregularmente estriado no sentido longitudinal (Figuras 1C e 1D), por vezes com rugas no sentido transversal, não sofrendo esfoliação com o tempo. Quando seccionadas longitudinalmente (Figura 1E) mostram-se compostas por uma região periférica ou casca, composta pela periderme, córtex e floema, e uma região central lenhificada, o xilema. A primeira apresenta sabor levemente adstringente e adocicado, textura macia e coloração marrom-avermelhada. Por sua vez, a porção central é totalmente insípida, apresentando-se com coloração amarelada, uniforme quando fresca, mas tornando-se marrom escura após o processo de fixação. Em várias amostras a casca destaca-se em placas finas ou apresenta fraturas longitudinais, parciais ou totais, deixando o xilema descoberto.

Após o processo de secagem, as raízes apresentam-se levemente retorcidas (Figuras $1 \mathrm{G}$ e $1 \mathrm{H}$ ) e com fratura completa do tipo granulosa. As estriações do súber perduram (Figuras 1F e 1G), podendo surgir fissuras transversais com o processo de fragmentação. Ao serem seccionadas longitudinalmente possibilitam a visualização de ambas as regiões acima descritas, estando a casca reduzida a poucos milímetros de espessura (Figura 1H). Raramente foram observadas cicatrizes de raízes secundárias, podendo ser punctiformes ou ovaladas (Figura 1G).

A análise ao microscópio óptico revela que o súber das raízes de $H$. aphrodisiaca está composto por 5-8 camadas de células tabulares (Figura 2A), com proeminente espessamento na parede periclinal interna (Figura 2B), na qual pontoações são facilmente visualizadas. Ao serem expostas ao cloreto férrico, suas células adquirem coloração intensa, negro-esverdeada, comprovando a presença de polifenóis, à semelhança dos resultados observados por Mazzoni-Viveiros e Costa (2003) em secções da periderme caulinar de duas espécies de Sclerolobium e uma de Enterolobium, pertencentes à família das leguminosas, indicando a função protetora, deste sistema de revestimento, contra o ataque de patógenos e herbívoros.

A região cortical das raízes encontra-se formada por células parenquimáticas de formatos variados, de isodiamétricas a alongadas (Figuras 3A e 3B), sempre e de lume aproximadamente circular em secção tangencial (Figura 3C), deixando entre si, espaços intercelulares de pequenas dimensões.

O floema secundário das raízes de $H$. aphrodisiaca apresenta-se com raios parenquimáticos uni a trisseriados, cujas células são volumosas (Figura 4A). Muitas delas contêm drusas e cristais prismáticos de oxalato de cálcio (que se dissolvem na presença de solução de ácido sulfúrico, sem efervescência). As drusas tornam-se ainda mais evidentes nas secções longitudinais, quando se apresentam, na maioria das vezes, enfileiradas ou agrupadas (Figuras 4B e 4C).

De acordo com a Figura 3B são as células parenquimáticas próximas dos raios floemáticos que sofrem divisões em planos diversos, contribuindo para a formação do abundante córtex e conseqüente tuberização da raiz. Não foram observados elementos de sustentação ou qualquer tipo de espessamento secundário nas paredes celulares desta porção radical.

Por toda região cortical e floemática não foram 
identificados grãos de amido ou gotículas lipídicas. Entretanto, a exposição destes tecidos ao cloreto férrico confirmou como polifenóis o conteúdo das células parenquimáticas, tanto as adjuntas ao floema quanto as do córtex em geral, que se mostravam com conteúdo marrom-alaranjado nas secções obtidas das amostras mantidas fixadas em etanol $70 \%$ (não expostas a outros reagentes). Tais substâncias também puderam ser evidenciados em células isoladas dos raios parenquimáticos do xilema secundário.

O xilema secundário apresenta-se muito compacto e rico em fibras gelatinosas (Figura 5) com pontoações evidentes em suas paredes (Figura 5C). De acordo com Fahn (1990), nas fibras gelatinosas a camada mais interna da parede secundária (camada G) há abundância de $\alpha$-celulose e pouca lignina, o que lhe permite absorver água, por vezes obliterando o lume celular. Na presença de cloreto de zinco iodado, esta camada interna cora-se em azul acinzentado, confirmando a presença de celulose e contrastando com a camada mais externa, que se apresenta na cor amarela, característica da presença de lignina.

$\mathrm{Na}$ região de constrição das raízes, as fibras gelatinosas mostram-se ainda mais compactadas (Figura $5 \mathrm{~A})$ e os raios parenquimáticos com células menores que nas porções mais tuberizadas (Figuras 5B e 5C). Tanto nesta quanto nas regiões tuberizadas notam-se os anéis de crescimento do xilema secundário (Figuras 5A, 5B e $5 \mathrm{C})$. Fibras semelhantes às da espécie em questão foram observadas por Paviani (1978) nos sistemas subterrâneos de espécies do cerradão brasileiro, possivelmente com função de reserva de água, tendo em vista a hidrofilia da camada celulósica. A ocorrência de H. aphrodisiaca, neste mesmo bioma, sugere maior atenção quando a possibilidade de adulterações das amostras desta droga vegetal com outras espécies vegetais com adaptações semelhantes, o que dificultaria a diagnose anatômica e o seu controle de qualidade.

Em secção transversal, os raios parenquimáticos desta raiz mostram-se unisseriados, raramente bisseriados (Figura 5B), compostos por células de volumes diversos (Figuras 5A, 5B e 5C). Quanto aos elementos de vaso, na maioria das vezes estão solitários, mas podem ocorrer conjugados dois a dois (Figura 5B), sempre com placas de perfuração simples e, na Figura 6B ficam evidenciadas suas pontoações areoladas. De acordo com Alves e Angyalossy-Alfonso (2000) as duas primeiras características são consideradas comuns nas madeiras de muitas espécies brasileiras.

Ainda em relação aos raios parenquimáticos, em secções tangenciais (Figura 6A) e radiais (Figuras 6B e 6C), verifica-se que suas células são retangulares, com paredes espessadas, deixando evidentes muitas pontoações. Quanto às fibras gelatinosas deste tecido, de acordo com a Figura 6C, subdividem-se em grupos, formando arranjos ramificados característicos com as células dos raios parenquimáticos.
A análise do pó diafanizado das raízes de $H$. aphrodisiaca revela que as drusas, os fragmentos de súber, os elementos de vaso com pontoações areoladas e os grupos de fibras gelatinosas com arranjo ramificado podem ser facilmente reconhecidos, enquanto que as células corticais não se reidratam durante o processo, permanecendo disformes, indicando que a metodologia aplicada não se mostra adequada para este tipo celular.

\section{Controle físico-químico}

A análise físico-química das raízes de $H$. aphrodisiaca revela que a perda por dessecação $(\mathrm{n}=5)$, a $105{ }^{\circ} \mathrm{C}$, mostra variações entre as coletas realizadas nos anos de 1998 e 1999, sendo de $15,8 \pm 0,6 \%$ (CV\% $=3,5)$ no verão, $13,6 \pm 0,08(\mathrm{CV} \%=0,9)$ na primavera, $9,4 \pm 0,2 \%(\mathrm{CV} \%=1,7)$ no outono e $7,5 \pm 0,1 \%(\mathrm{CV} \%$ $=1,3)$ no inverno, tendo sido mantidas nas mesmas condições de armazenagem. Estes dados demonstram que as raízes apresentam uma maior capacidade de armazenagem de água e outras substâncias voláteis nos períodos do verão e da primavera, respectivamente, provavelmente relacionada com o período de chuva da região, que ocorre de setembro a março.

A triagem química preliminar mostra a presença de flavonóides, substâncias antracênicas, esteroidais e taninos nas amostras das raízes coletadas nas diferentes estações do ano, confirmando os resultados obtidos por Galvão et al. (2002).

Pela análise cromatográfica, em camada delgada, estabelece-se que as substâncias neoastilbina, astilbina e isoastilbina, isoladas do extrato hidroalcoólico das raízes, apresentam valores de $\mathrm{R}_{\mathrm{f}}$ de 0,60, 0,68 e 0,74, respectivamente, frente aos reveladores empregados. Quanto ao tempo de retenção das três substâncias por cromatografia líquida de alta eficiência, observa-se: $16,44 \mathrm{~min}$ (10,7\% teor em relação ao extrato); $16,91 \mathrm{~min}$ (16,3\% teor em relação ao extrato) e 18,08 $\min (5,5 \%$ teor em relação ao extrato), respectivamente (Figura 7).

De acordo com a Tabela 1 , verifica-se que a água é o melhor líquido extrator das substâncias presentes nas raízes de "nó-de-cachorro", no que se refere ao teor de sólidos extraíveis (média de 44,5\%), demonstrando a presença de substâncias de alta polaridade em grande quantidade nas raízes deste vegetal.

Quanto à extração de substâncias com outros solventes, verifica-se que o uso das misturas hidroetanólicas foram as mais indicadas para as amostras obtidas no verão e na primavera; enquanto que para as amostras obtidas no outono e inverno, a mistura acetona:água (1:1) apresenta-se como a mais adequada (Tabela 1).

Ainda de acordo com a Tabela 2, os índices de espuma obtidos para o decocto das amostras de raízes, nas quatro estações do ano, atestam que a presença de substâncias do tipo saponinas não é expressiva quantitativamente nesta droga vegetal, apresentando-se 
em maior quantidade no verão. Tais substâncias devem ser notadas, pois correspondem a uma das classes mais intrinsecamente relacionadas aos reputados efeitos adaptógenos, como ocorre com as saponinas presentes no ginseng coreano (Panax ginseng C.A. Mey.) e também no ginseng brasileiro [Pfaffia glomerata (Spreng.) Pedersen] (Vigo et al., 2004).

Além da comprovação pelos testes microquímicos com cloreto férrico, a intensa coloração marrom-avermelhada e adstringência dos extratos das raízes auxiliam na confirmação da presença de altos teores em polifenóis totais obtidos nos extratos. Assim, podem ser considerados relativamente altos, e indicativos de que tanto a primavera como o outono podem ser consideradas as épocas mais adequadas para a obtenção destas substâncias nas raízes.

Para o controle de qualidade da droga vegetal o diâmetro médio $\left(\mathrm{d}_{50}\right)$ de partículas $(\mathrm{mm})$ das raízes, após moagem e tamisação, foi estabelecido em 0,$47 ; 0,72$;
0,89 e 0,91 , respectivamente, para as amostras obtidas no verão, primavera, outono e inverno (Tabela 2). Podese observar que conforme o $d_{50}$ aumenta, a quantidade de água retida (perda por dessecação) nas amostras diminui, não demonstrando, entretanto, relação com o teor de polifenóis totais.

\section{CONCLUSÃO}

Conclui-se que, do ponto de vista morfoanatômico, as raízes de $H$. aphrodisiaca apresentam características peculiares, tais como seu formato alongado com constrições; o súber com espessamento proeminente apenas na parede anticlinal interna; o córtex formado por muitos estratos celulares de parede finas e com drusas em abundância, e especialmente as fibras gelatinosas com arranjo ramificado, dados que dificultam a adulteração por outras drogas vegetais, como Vernonia cognata. Os resultados das análises

Tabela 1. Teor de extrativos médio, em porcentagens, das raízes de Heteropteris aphrodisiaca empregando-se diferentes líquidos extratores $(\mathrm{n}=5)$.

\begin{tabular}{lccccc}
\hline & \multicolumn{5}{c}{ Estações do ano } \\
\cline { 2 - 6 } \multicolumn{1}{c}{ Líquido extrator } & $\begin{array}{c}\text { Verão } \\
(\%)\end{array}$ & Primavera (\%) & $\begin{array}{c}\text { Outono } \\
(\%)\end{array}$ & $\begin{array}{c}\text { Inverno } \\
(\%)\end{array}$ & $\begin{array}{c}\text { Valor } \\
\text { médio (\%) }\end{array}$ \\
\hline água & 31,2 & 47,2 & 50,9 & 48,7 & 44,5 \\
etanol:água (1:1) & 42,6 & 36,8 & 40,2 & 38,4 & 39,5 \\
metanol:água (1:1) & 39,6 & 35,7 & 38,5 & 36,5 & 37,6 \\
acetona:água (1:1) & 42,5 & 35,1 & 42,7 & 42,2 & 40,6 \\
acetona:água (7:3) & 36,5 & 33,0 & 38,9 & 37,9 & 36,6 \\
\hline
\end{tabular}

A Tabela 2 apresenta os dados obtidos quanto aos parâmetros cinzas, índice de espuma, polifenóis totais e granulometria. Os teores de cinzas totais e insolúveis obtidos em amostras coletadas nas diferentes épocas do ano demonstram que, apesar da droga ser uma raiz, não apresenta um alto teor de substâncias inorgânicas (cinzas fisiológicas e não fisiológicas), estando os valores obtidos dentro dos padrões de drogas vegetais da Farmacopéia Brasileira.

Tabela 2. Valores médios do teor de cinzas totais e insolúveis, índice de espuma, teor em polifenóis totais e granulometria média obtidos das raízes de Heteropteris aphrodisiaca $(\mathrm{n}=5)$.

\begin{tabular}{lcccc}
\hline \multirow{2}{*}{ Teores } & \multicolumn{4}{c}{ Estações do ano } \\
\cline { 2 - 5 } & Verão & Primavera & Outono & Inverno \\
\hline Cinzas Totais $(\bar{x} \pm d p)[\mathrm{CV} \%]$ & $3,4 \pm 0,2[6,2]$ & $4,1 \pm 0,1[2,8]$ & $5,3 \pm 0,05[0,8]$ & $4,7 \pm 0,1[3,3]$ \\
Cinzas Insolúveis $(\bar{x} \pm d p)[\mathrm{CV} \%]$ & $1,3 \pm 0,08[5,9]$ & $0,4 \pm 0,2[37,8]$ & $0,6 \pm 0,1[22,9]$ & $0,6 \pm 0,1[22,2]$ \\
Índice de Espuma & 250 & 100 & 125 & 167 \\
Polifenóis Totais $(\bar{x} \pm d p)[\mathrm{CV} \%]$ & $7,9 \pm 0,09[1,1]$ & $10,2 \pm 0,06[0,5]$ & $9,8 \pm 0,2[2,1]$ & $5,3 \pm 0,1[1,9]$ \\
Granulometria $\left(\mathrm{d}_{50}\right)(\mathrm{mm})$ & 0,47 & 0,72 & 0,89 & 0,91 \\
\hline
\end{tabular}



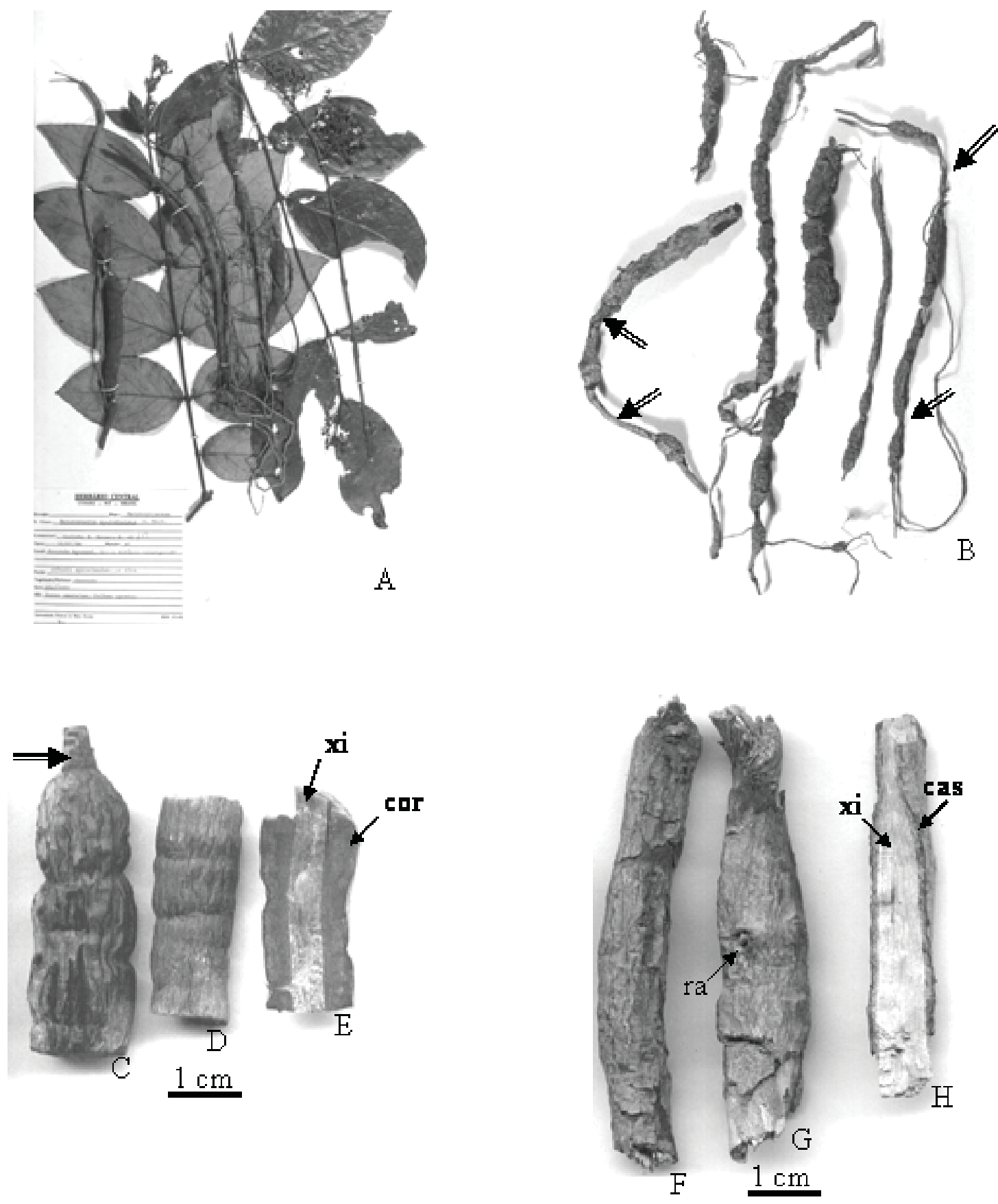

Figura 1. Exsicata de Heteropteris aphrodisiaca (A), amostras de raízes secas (B), detalhes das mesmas quando fixadas (C, D e E) e secas (F, G e H). Notam-se o córtex espesso (cor) (E), súber estriado (C, D, F e G), casca (cas), xilema (xi) e a cicatriz de uma raiz lateral (ra). As setas duplas indicam as regiões de constrição. 

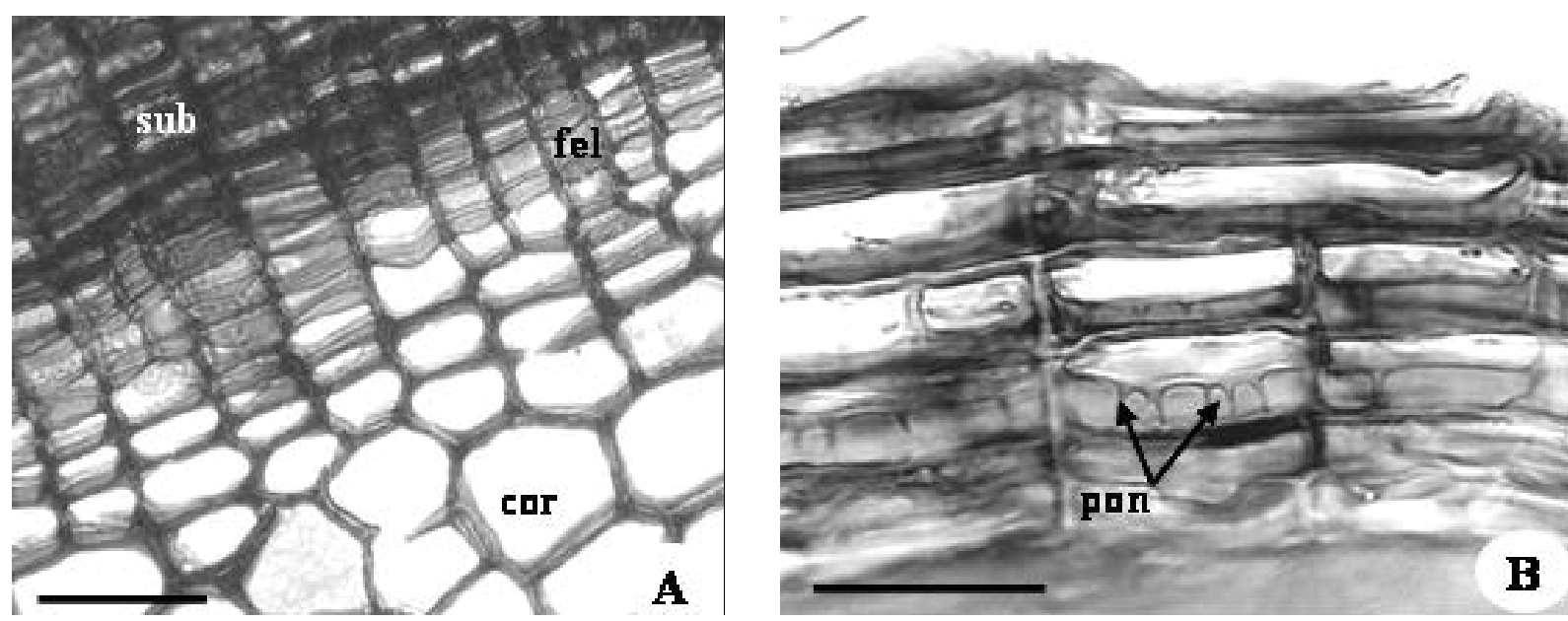

Figura 2. Região da periderme e do córtex da raiz de Heteropteris aphrodisiaca (A) e detalhe das células do súber (B). cor: córtex, fel: felogênio, pon: pontoações, sub: súber. Barra de A: $50 \mu \mathrm{M}, \mathrm{B}: 20 \mu \mathrm{M}$.
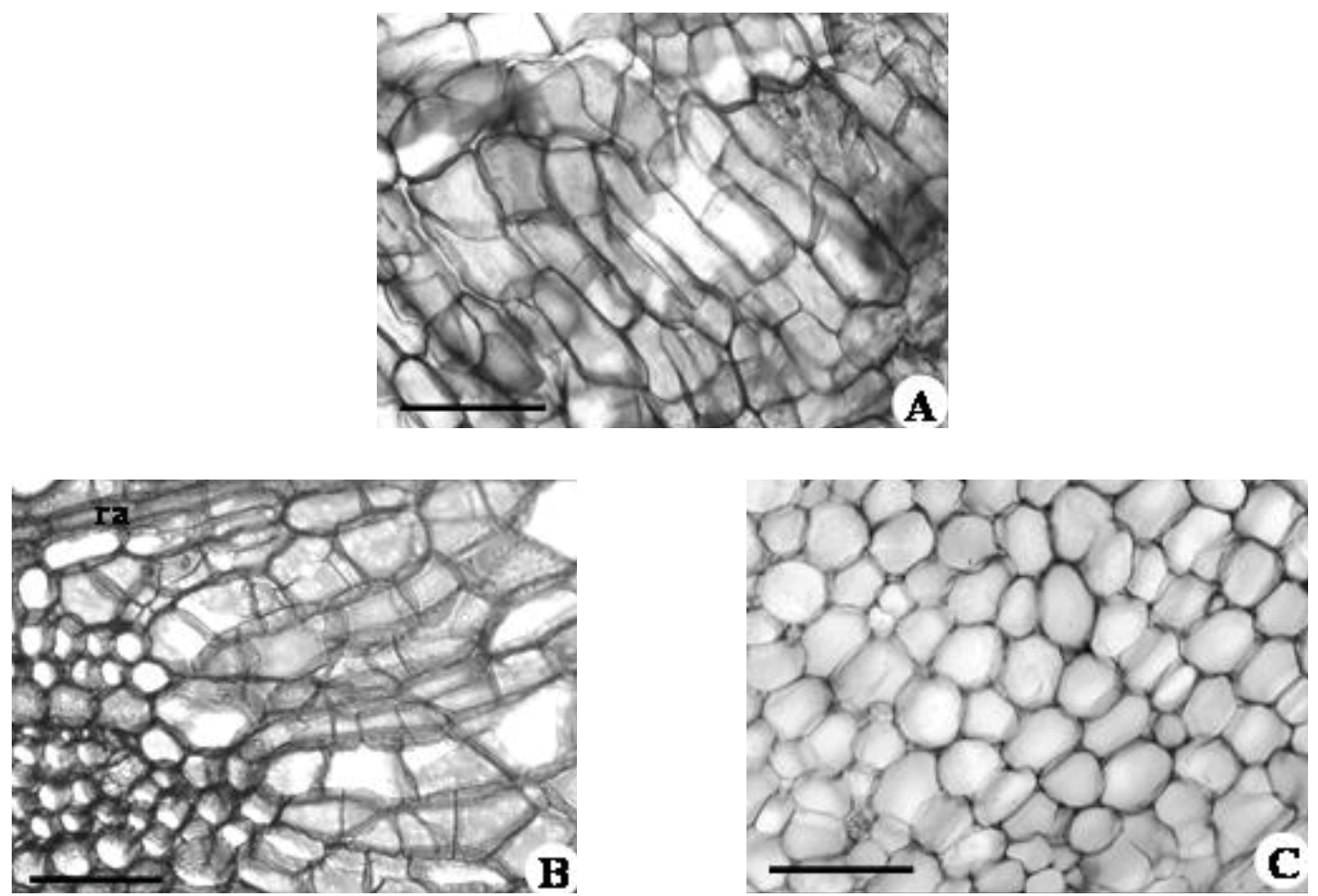

Figura 3. Raiz de Heteropteris aphrodisiaca. Secções transversais da região cortical mais periférica (A) e mais próxima ao floema (B). Em C: secção tangencial das células corticais. ra: raio parenquimático. Barras: $100 \mu \mathrm{M}$. 

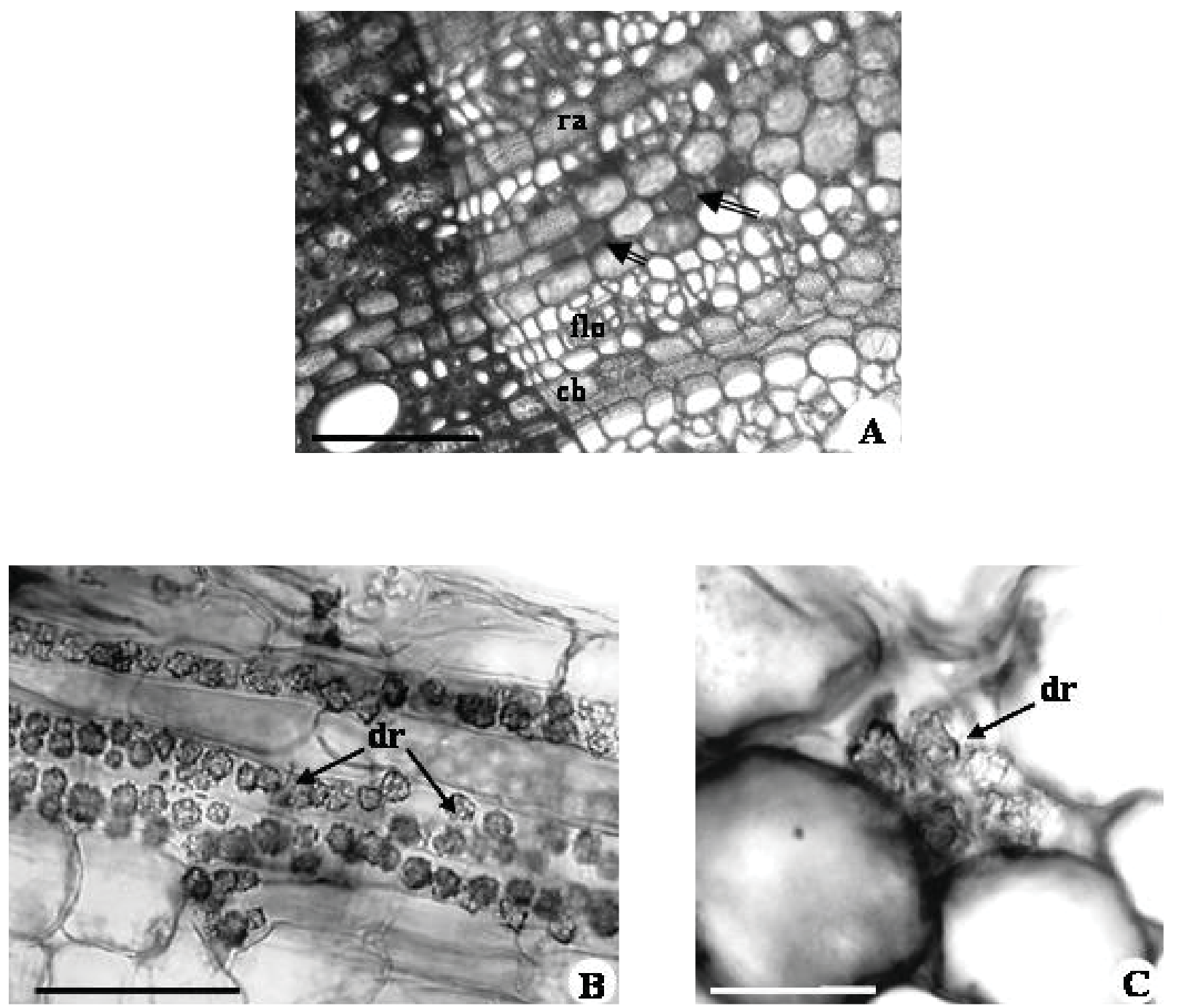

Figura 4. Secção transversal na região do cilindro vascular da raiz de Heteropteris aphrodisiaca (A) e secções longitudinais na região floemática (flo) (B e C) evidenciando drusas (dr). cb: câmbio vascular, ra: raio parenquimático, xi: xilema secundário. As setas duplas indicam idioblastos com drusas. Barra de A: $100 \mu \mathrm{M}, \mathrm{B}: 50 \mu \mathrm{M}$ e C: $20 \mu \mathrm{M}$. 



Figura 5. Secções transversais do xilema secundário das raízes de Heteropteris aphrodisiaca. Região de constrição (A), região tuberizada (B) e detalhe das fibras gelatinosas (fb) e raios parenquimáticos (ra) (C). ev: elemento de vaso. As setas simples indicam os anéis de crescimento, e a dupla um raio bisseriado. Barras: $50 \mu \mathrm{M}$. 

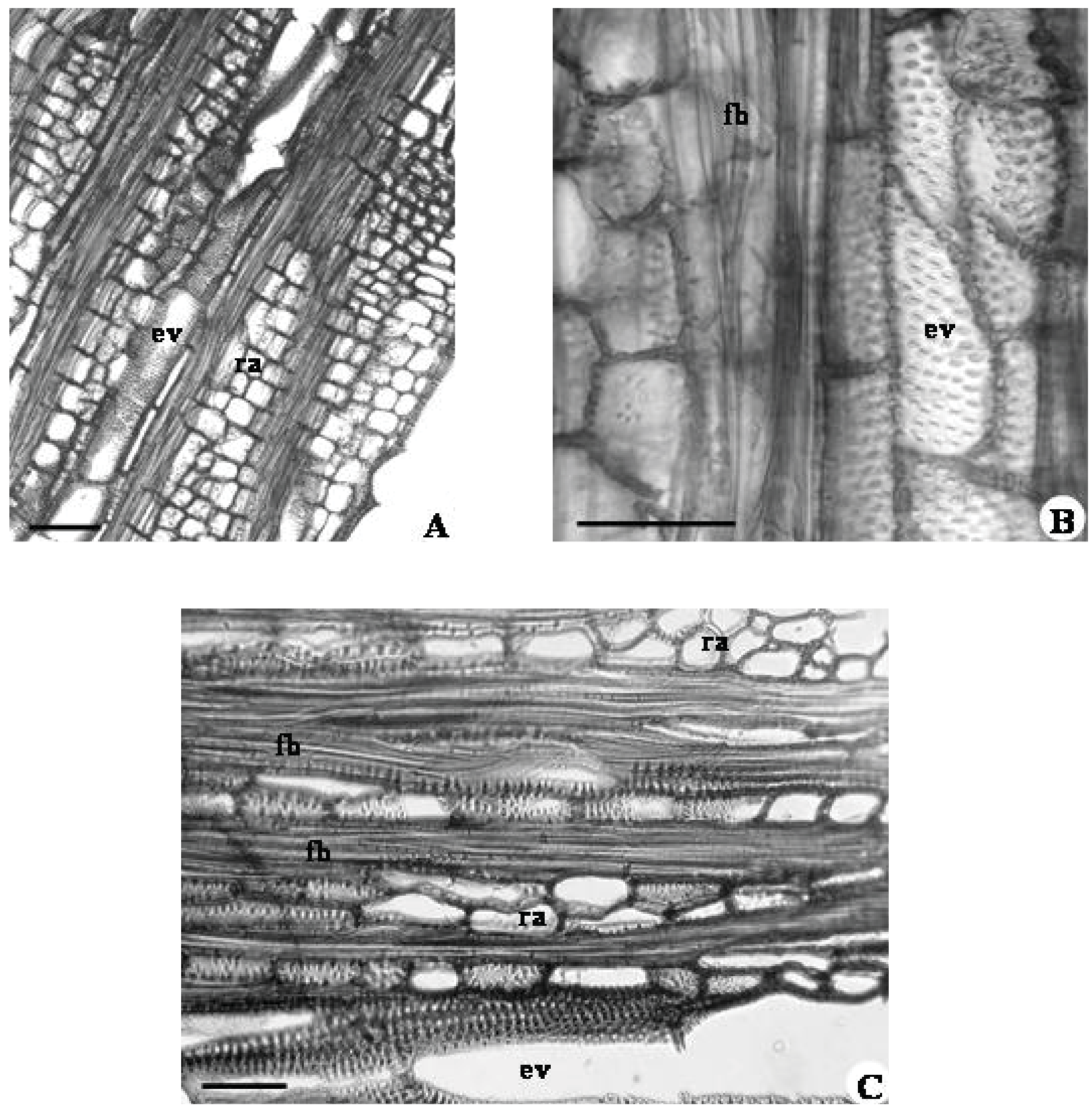

Figura 6. Secções tangencial (A) e radial do xilema secundário das raízes de Heteropteris aphrodisiaca (B e C). Aspecto geral (A), detalhe dos elementos de vaso (ev) (B) e do arranjo das fibras gelatinosas (fb) (C). ra: raio parenquimático. Barras de A e C: $100 \mu \mathrm{M}$ e B: $50 \mu \mathrm{M}$. 

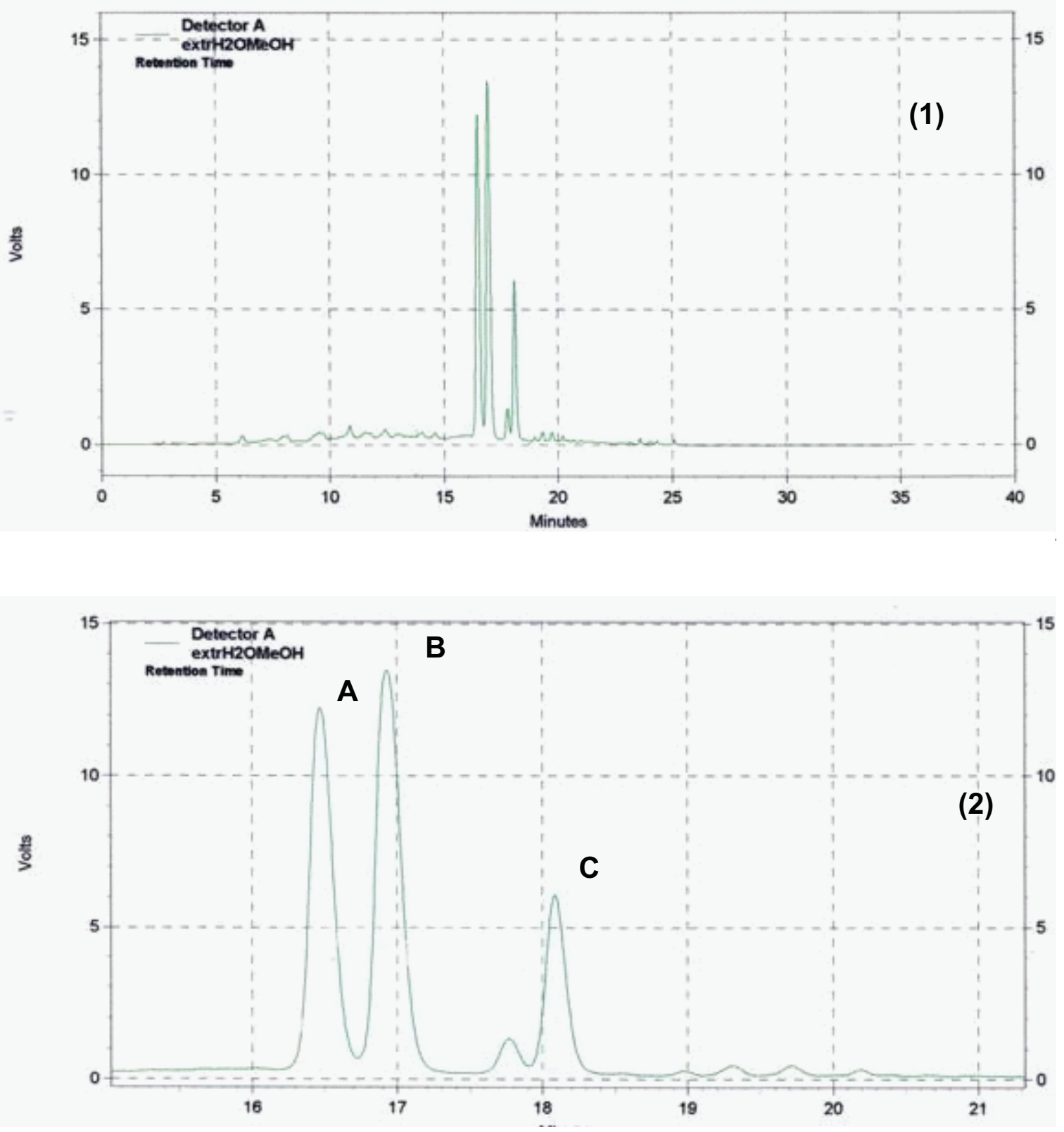

Figura 7. Cromatografia líquida de alta eficiência: cromatograma geral (1) e ampliado (2) dos flavonóides neoastilbina (A; 16,44 $\min$ ), astilbina $(\mathbf{B} ; 16,91 \mathrm{~min})$ e isoastilbina $(\mathbf{C} ; 18,08 \mathrm{~min})$, da fração acetato de etila obtida a partir do extrato hidroetanólico a 50\% $(10 \% ; \mathrm{p} / \mathrm{v})$. Condições cromatográficas: Coluna RP-18 Phenomenex ${ }^{\circledR},(250$ x 4,6 mm d.i.; $5 \mu \mathrm{M})$; fase móvel: sistema gradiente multilinear: bomba A: ácido acético 5\%; bomba B: MeOH 10\% (5 min), 50\% (15 min), 100\% (20-25 min), MeOH 50\% (30 min) e MeOH 10\% (40 min); vazão: 1,2 mL/min; detecção: $280 \mathrm{~nm}$. 
físico-químicos permitem propor parâmetros máximos e mínimos para a droga vegetal, da seguinte forma: cinzas totais: máximo 6\%; cinzas insolúveis em ácido: máximo $1,5 \%$; teor de extrativos aquoso a quente: mínimo $30 \%$; índice de espuma: mínimo 100; e polifenóis totais: mínimo 5\%. A análise cromatográfica em camada delgada e/ou por cromatografia líquida de alta eficiência com o uso dos marcadores flavonoídicos neoastilbina, astilbina e isoastilbina auxiliam na identificação da droga vegetal.

\section{AGRADECIMENTOS}

Agradecemos à Dr ${ }^{\mathrm{a}}$. Miramy Macedo, do Instituto de Botânica da UFMT pelo exame das amostras de H. aphrodisiaca utilizadas neste estudo e à Dra ${ }^{\text {a }}$ Maria Cândida Henrique Mamede, especialista na família Malpighiaceae, do herbário do Instituto de Botânica de São Paulo, pela identificação das amostras. Ao $\mathrm{CNPq}$ pelo auxílio de bolsa de iniciação científica. Ao apoio técnico de Admir Arantes e Cláudio Roberto Novello.

\section{REFERÊNCIAS}

Alves ES, Angyalossy-Alfonso V 2000. Ecological trends in the wood anatomy of some Brazilian species. I: Growth rings and vessels. Iawa J 21: 3-30.

Corrêa MP 1984. Dicionário das plantas úteis do Brasil e das exóticas cultivadas. v.5. Rio de Janeiro: Ministério da Agricultura. 687p.

Fahn A 1990. Plant anatomy. 4.ed. New York: Pergamon Press. 611p.

Farmacopéia Brasileira. 4.ed. São Paulo: Atheneu, 1998. v.4. Galvão SMP, Dias RF, Espínola EB, Marques LC, Mattei R, Carlini EA 1996. Avaliação farmacológica de plantas medicinais brasileiras com possível efeito adaptógeno - I: estudos preliminares. XIV Simpósio Brasileiro de Plantas Medicinais. Florianópolis, Brasil.

Galvão SMP, Marques LC, Oliveira MGM, Carlini ELA 2002. Heteropterys aphrodisiaca (extract BST0298): a Brazilian plant that improves memory in aged rats. $J$ Ethnopharmacol 79: 305-311.

Glasl H 1983. Zur photometrie in der Drogenstandardisierung - 3. Gehealtsbestimmung von Gerbstoffdrogen. Dtsch Apoth Ztg 123: 1979-1987.

Handro W 1967. Contribuição ao estudo da venação e anatomia foliar das Amarantáceas do cerrados II. Gênero Pffafia. An Acad Bras Cienc 39: 495-506.

Harborne JB 1998. Phytochemical methods: a guide to modern techniques of plant analysis. London: Chapman \& Hall.

Hoehne FC 1920. O que vendem os hervanários da cidade de São Paulo. São Paulo: Serviço Sanitário do Estado de São Paulo. 248p.

Johansen DA 1940. Plant microtechnique. New York: McGraw-Hill. 523p.

Kraus J, Arduin M 1997. Manual básico de métodos em morfologia vegetal. Seropédica: EDUR. 198p.

Machado OXB 1948-1949. Nova espécie do gênero Heteropteris Kunth. Rodriguésia 11-12: 111-119.
Marques LC, Galvão SMP, Peres PG, Rebecca MA, Mello JCP 1996. Caracterização farmacognóstica da droga vegetal "nó-de-cachorro" (Vernonia cognata Less. Asteraceae). XIV Simpósio de Plantas Medicinais do Brasil. Florianópolis, Brasil.

Mattei R, Galvão SMP, Barros MP, Bechara EJH, Carlini ELA 2001. Heteropteris aphrodisiaca O. Machado: Effects of extract BST 0298 on the oxidative stress of young and old rat brains. Phytother Res 15: 604-607.

Macedo M, Ferreira AR 2004. Plantas hipoglicemiantes utilizadas por comunidades tradicionais na Bacia do Alto Paraguai e Vale do Guaporé, Mato GrossoBrasil. Rev Bras Farmacogn 14(Supl. 1): 45-47.

Mazzoni-Viveiros SC, Costa CG 2003. Periderme. In: Appezzato-da-Costa B, Carmello-Guerreiro SM (org.) Anatomia vegetal. Viçosa: UFV. p.237-263.

Melo FL, Benati FJ, Roman-Júnior WA, Mello JCP, Nozawa C, Linhares REC 2006. The in vitro antiviral activity of an aliphatic nitro compound from Heteropteris aphrodisiaca. Microbiol Res doi:10.1016/j.micres.2006.03.011.

Oliveira F, Akisue G, Akisue MK 1991. Farmacognosia. São Paulo: Atheneu. p. 244-246.

Paviani TI 1978. Anatomia vegetal e cerrado. Cienc Cult 30: 1076-1086.

Rizzini CT, Mors WB 1976. Botânica econômica Brasileira. São Paulo: EPU/EDUSP. p. 84.

Rizzini CT 1983. Efeitos psicotrópicos de plantas brasileiras. Parte II: aspectos botânicos. Cienc Cult 35: 434-438.

Roman-Júnior WA 2003. Identificação de nitrocomposto $e$ di-hidroflavonóis, atividades antibacteriana, antifúngica e antiviral de substâncias isoladas dos extratos liofilizados das raizes de Heteropteris aphrodisiaca O. Mach., Malpighiaceae, Nó-deCachorro. Araraquara, 132p. Dissertação de Mestrado - Programa de Pós-Graduação em Ciências Farmacêuticas, Universidade Estadual Paulista "Júlio de Mesquita Filho".

Roman-Júnior WA, Cardoso MLC, Vilegas W, Nakamura CV, Dias-Filho BP, Mello JCP 2005. 2,3,4,6-Tetra$O$-(3-nitropropanoyl)- $O$ - $\beta$-D-glucopyranoside, a new antimicrobial from the roots of Heteropteris aphrodisiaca. Acta Farm Bonaerense 24: 543-545.

Vigo CLS, Narita E, Milaneze-Gutierre MA, Marques LC 2004. Caracterização farmacognóstica comparativa de Pfaffia glomerata (Spreng.) Pedersen e Hebanthe paniculata Martius - Amaranthaceae. Rev Bras Plant Med 6: 7-19.

Wagner H, Bladt S, Zgainski EM 1983. Drogen analyse. Berlin: Springer Verlag. p.304.

WHO, World Health Organization 1992. Quality control methods for medicinal plant material. WHO: Geneva. $115 \mathrm{p}$. 